\title{
Study of rigid Bolt Joint in Beam-column connection of Gabled Portal Frames
}

\author{
Xuan Guo ${ }^{1, a}$, Xiaoxin Zhang ${ }^{2, b}$ \\ ${ }^{1}$ School of Civil Engineering, Beijing Jiaotong University, Beijing 100044, China \\ 2 Design Group Corporation Limited, Beijing 100037 \\ aemail:xguo@bjtu.edu.cn, bemail: fx2002@163.com
}

Keywords: Gabled Portal Frames; Rigid Joint Of Beam-Column Connection; Extended End Plate; Inclined Stiffener; Mechanics Model

\begin{abstract}
The mechanical model analysis of the rigid joint of the key beam column connection of the portal frame of the industrial building is given in this paper.The structure form of joint has great influence on the stress state of high strength bolt connection. The calculation model of bolt is matched according to the actual structure. The mechanical analysis of the components joint using the finite element software SAP2000 is given by choosening the model of rigid stiffener extended end plate connection. The results show that the tension value of the two row of bolts on the side of the rigid joint model is close to each other.The tension of the first row of bolts on the side of the tension flange is always in the extreme value, which could be considered for the design envelope value.There is no obvious change in the tension force of the flange side of the compression flange if ignoring the impaction of the pull bending force,which satisfies the plane section assumption. The numerical simulation results verify the applicability of the proposed model for the design of high strength bolt rigid joints.
\end{abstract}

\section{Introduction}

The design of portal frame beam column connection joint is a very important part in the whole design process,node design directly affects the stability, reliability, construction period and cost of the whole building structure.

The bolted end plate connection of beam-column has been widely used, but the design and the calculation methods have not yet formed the common model and parameters. Portal frame technical procedures[1] in the relevant measures are not fully complete yet. Beam design of column connections often fails to meet the requirement of stiffness joint based on experience design or engineering analogy.Triditional beam column joints lead to reliability problem of portal rigid frame structure happened now and then according to the ideal frame calculation method[2].Most light portal frame structure load is small,the earthquake action is very small, which generally does not have the control function. It is not needed to design a energy dissipational semi-rigid joint in the most cases, the rigid joint should be designed as comparison and simplification study.

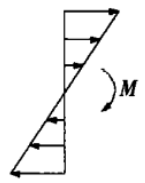

A

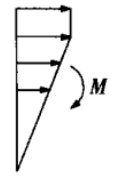

B

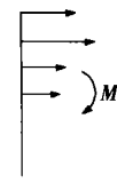

$\mathrm{C}$

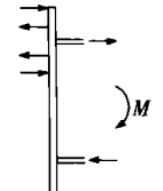

$\mathrm{D}$

A-China specification;B:-UK specification; C-European specification; D-United States specification

Fig1.Typical node calculation model

The connection design of beam column end plate high strength bolt, the bolt calculation stress model is shown in Fig.1.For the extended end plate connection cases, all bolt force model overestimated the tension stress of the second rows bolt[3].The end plate inclined joint connection[4] extended and the maximum pull force on the 2nd rows of bolts (i.e. the first row bolts of the tensile flange inside ).The tension and bending moment of the first rows of bolts are very large, and the 
tension and bending moment of the second row bolts are very small[3].Then ,the connection form of joint structure has great influence on the stress state of bolt, and the calculation model of different bolt should be selected according to different structure forms [1-5].

More research on bolted end plate connection mainly on semi-rigid joints ([4], [6]),but the study of rigid connection of bolted end plate is few. Finite element simulation analysis make up the lack of experimental research to a certain extent, it can help to accurate and comprehensive understanding the details of the end plate connection. In this paper, the finite element software SAP2000 (V.14.2) is used for simulation analysis, the stress characteristics of bolted end plate connection of portal rigid frame beam column connections is studied.

\section{Selection of the Rigid Node}

The total stiffness of the joint is composed of two parts, the stiffness of the joint domain and the connection stiffness.End plate bending stiffness or column web shear stiffness is larger, the initial node rotation stiffness is more larger, the distance between outer bolt to the beam flange is larger, the joint stiffness is smaller.Extended the end plate stiffener part can improve the bearing capacity of the joint structure and increase joint stiffness. So the thickness of the end plate can be reduced properly[7-8]。

The end plate can prevent the shear deformation of the column web, the bearing capacity of the column web is increased with the increase of thickness of the end plate.The diagonal stiffening rib is arranged in the column web plate of joint domain, which can effectively improve the shear deformation capacity and increase the stiffness of the joint domain.

More thicker of the end plate, more greater initial connection stiffness is. When the end plate is thin, the influence of the thickness of end plate on the initial connection stiffness of the joint is more obvious than the case of thicker end plate. When meet the requirements of the bearing capacity, the arrangement of 4 row of 8 bolt node is most reasonable. It can make full use of beam column material potential.

Select actual portal frame beams connecting joint and it's domain with diagonal stiffener, extended end-plate set stiffeners, steel columns and steel beam specifications are HN396 $\times 199 \times 7$ $\times 11$. Joint plate thickness are $26 \mathrm{~mm}$, rib thickness are $10 \mathrm{~mm}$, high-strength bolts specifications are M24, grade 10.9. Beam-column joints specific dimensions shown in Fig.2.
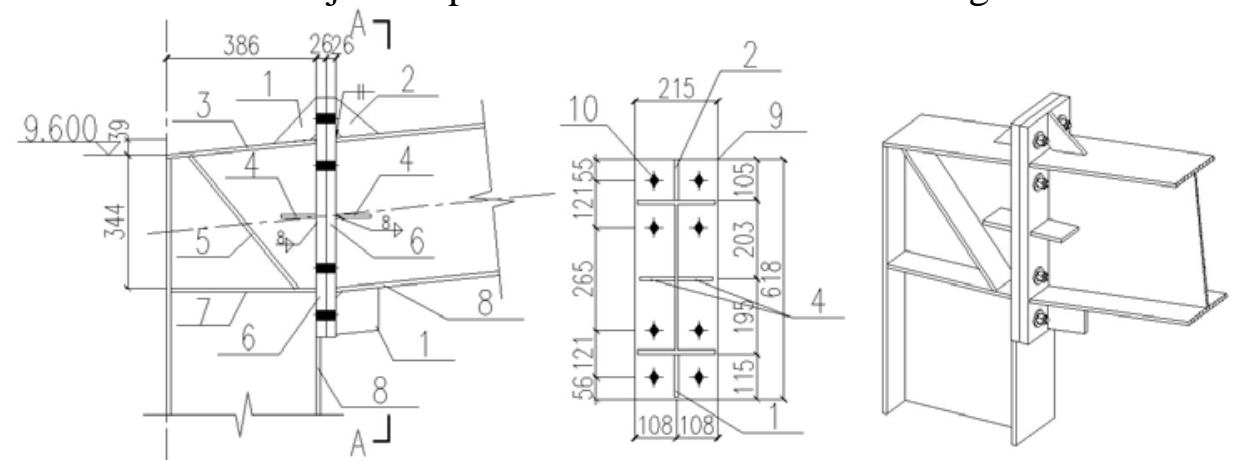

a- Beam-column joint b-Section A-A c-Isometric views of joint

$$
\begin{aligned}
& 1--10 \times 110, \mathrm{~L}=110 \mathrm{~mm} ; 2--10 \times 105, \mathrm{~L}=110 \mathrm{~mm} \text {; } \\
& 3--10 \times 199, \mathrm{~L}=387 \mathrm{~mm} ; 4--10 \times 90, \mathrm{~L}=90 \mathrm{~mm} ; \\
& 5--10 \times 96, \mathrm{~L}=437 \mathrm{~mm} ; 6--25 \times 215, \mathrm{~L}=518 \mathrm{~mm} ; \\
& 7--10 \times 96, \mathrm{~L}=374 \mathrm{~mm} ; 8-\mathrm{HN} 396 \times 999 ; \\
& 9--26 \times 215, \mathrm{~L}=618 \mathrm{~mm} ; 10-8-\mathrm{M} 24, \quad \text { F2 } 6
\end{aligned}
$$

Fig. 2 typical beam-column joints of portal frame

According to the literature [2] with diagonal stiffener joint domain rotational stiffness is calculated as follows:

$$
R_{1}=G h_{1} h_{0 c} t_{p}+E h_{0 b} A_{s t} \cos ^{2} \alpha \sin \alpha=131902 \mathrm{kN} \cdot \mathrm{m} / \mathrm{rad}
$$

The thickness of end-plate of beam-column connection in Fig. 2 is determined according to the 
formula 7.2.9-3a. When the thickness of the end-plate is calculated by the Standard[1] calculation value, the end plate is provided with the stiffening rib which has little effect on the stiffness of the joint [9]. Therefore, the effect of stiffening rib is not considered when calculating the connection stiffness. According to the literature [10] connection stiffness is calculated as follows:

$$
R_{2}=\frac{6 E I_{c} h_{1}^{2}}{1.1 e_{f}^{3}}=315236 \mathrm{kN} \cdot \mathrm{m} / \mathrm{rad}
$$

Connection stiffness is calculated as follows:

According to the EU steel structure design specification EC3[11], for the lateral frame, when the joint total rotational stiffness $R \geq 25 E I_{b} / l_{b}$ ( $I_{b}, l_{b}$, moment of inertia of the beam, span), it can be considered rigid joints.

The beam span $l_{b}=18 \mathrm{~m}, 25 E I_{b} / l_{b}=54427 \mathrm{kN} \cdot \mathrm{m} / \mathrm{rad}<R=92992 \mathrm{kN} \cdot \mathrm{m} / \mathrm{rad}$. Therefore, the selected beam column connection node is a rigid node. In addition, the column flange is in the same thickness as the end-plate, the end-plate is arranged in the beam web stiffeners range will improve joint stiffness (not taken into account when calculating).

\section{Establishment of finite element model}

In order to facilitate research on joint force characteristics under the action of bending moment, the finite element model simplified as follows: the bolt as a whole, and because the entire loading process, the bolt head and nut of the end plate has remained in close contact, when modeling, the contact analysis between bolt head and nut and end plate is not considered, and end plate glued (common node).

The joint is composed of two parts of the plate and bolt. In SAP2000, the object according to the mechanical characteristics of plates and shells can be divided into three categories: membrane, plate and shell element.

Beam column joints in addition to bolt using shell element to simulate; high-strength bolts linear element is used to simulate, without considering the its contact with the end plate (only affect the local stress distribution), bolts and end plate common node. According to the steel plate area represented by each node in the finite element model and the elastic modulus of steel, the parameters of the nonlinear connection spring are obtained. At the end of the column to impose a fixed constraint, set the end of the beam symmetry constraints. Beams steel column rigid connection node finite element model shown in Fig. 3.

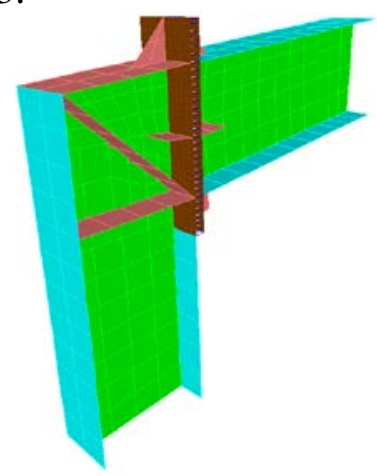

Fig.3 Finite element model of beam-column joint in portal frame

Steel material of joint calculation model is Q235B, the strength of steel and other parameters according to specifications [12] values. 10.9 high strength bolt preload according to the standard value of $225 \mathrm{KN}$. Bolt pre-tension applied by cooling to achieve.

The design moment of the joint is $\mathrm{M}=170 \mathrm{kN} \cdot \mathrm{m}$, but when the finite element calculation is carried out, in order to further study the bearing capacity of the joint, the moment loading value is set to $350 \mathrm{kN} \cdot \mathrm{m}$. The calculation process is divided into two load steps: the first load step is applied to the bolt preload load, the second load step using equal parts of ten load moment, until the ultimate load value. 


\section{Analysis of finite element model results}

The stress distribution of end plate is shown in Fig.4, units: MPa
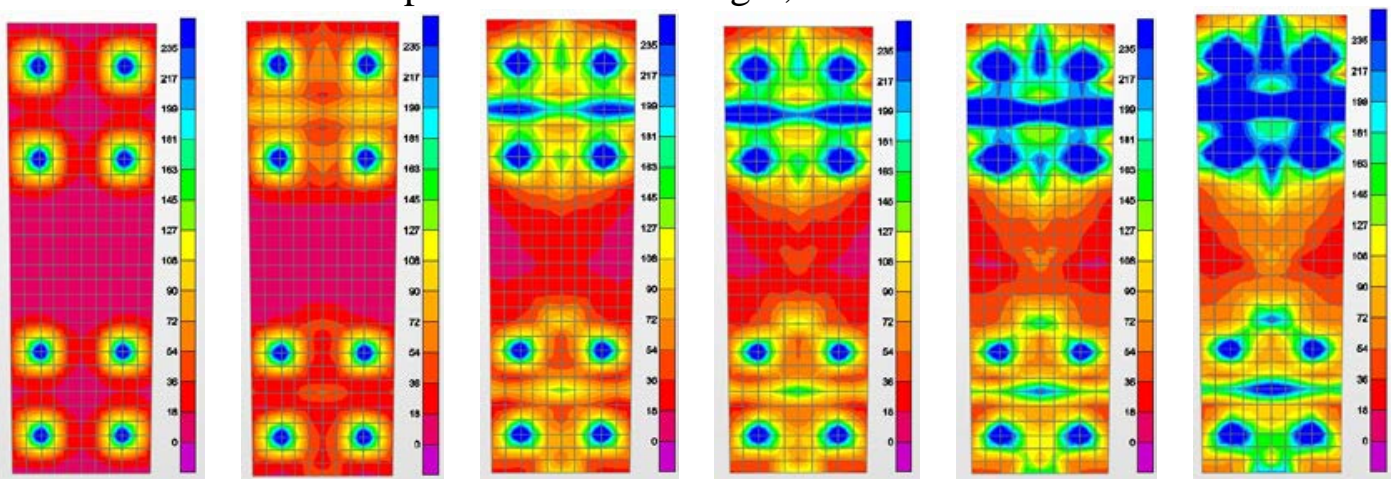

(a) plus bolt pre tightening force (b) preload + first step load (c) preload + fifth step load

(d) preload + sixth step load (e) preload + eighth step load (f) preload + tenth step load

Fig. 4 The stress distribution of the endplate

The stress near the end plate is close to the circular distribution under the effect of the initial bolt preload, and the closer to the edge of the hole, the greater the stress. With the increase of load, the pre pressure of the tension zone decreases gradually, but the bolt tension increases gradually, which is reflected by the stress significantly increased of the end plate tension zone in the bolt hole edge, the stress of the end plate near the bolts which in compression zone also increased.

Tension bolt and bolt spacing curve shown in Fig. 5, the Fig. 0-10 were loaded moment load steps.

Literature[4] through the portal rigid frame beam column bolted connections of semi-rigid joint, it thinks that joint rotation center is basically in the compression flange centerline. Literature [5] also proposed the rotation center of the joint in the position of the compression flange of the cross section. As it can be seen from Fig. 5, during the loading process, the center of the joint rotation is substantially in the middle of the compression flange (close to) near the first row of the bolt axis.

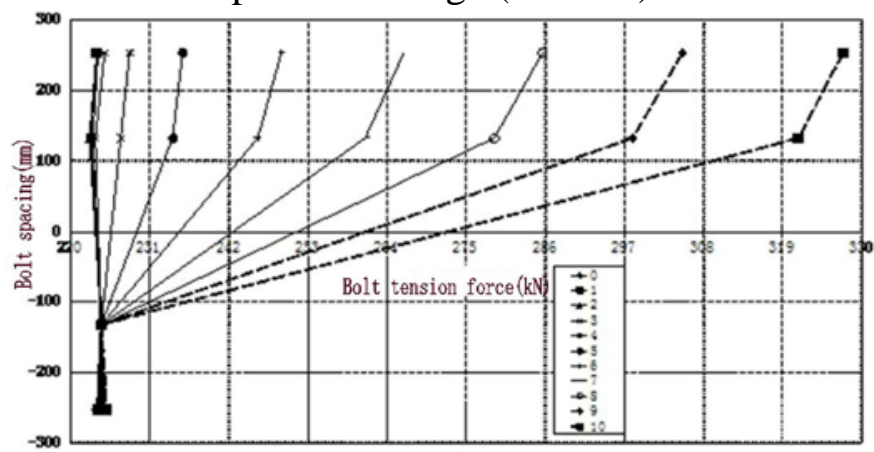

Fig.5 The curve of bolt tension force and bolt spacing

The relationship between bolt tension and bending moment is shown in Fig.6. The 1 to 4 of the bolts in the Fig. is indicated by the first row to the fourth row of bolts in the sequence of the tension zone to the compression zone.

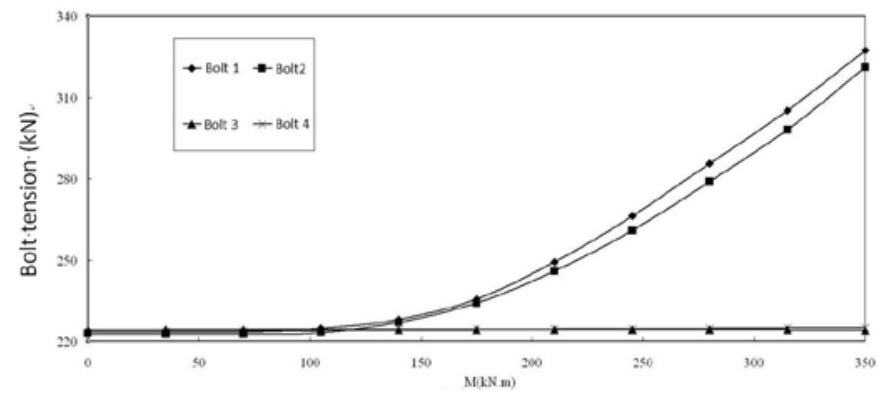

Fig. 6 The relationship between the bolt tension and bending moment

As it can be seen from Fig. 6, the joint before reaching the elastic limit load, bolt tension is relatively uniform, the difference is small. Since then, the bolts tensile growth rate is larger in 
tension flange, and there is little change in the tension of the bolt in the compression zone. First rows of bolts on the flange side of the tension is always the largest, the first row, second row of bolt tension is very close and when reached the design capacity, a difference of $0.6 \%$, the ultimate bearing capacity, a difference of $2 \%$. It can be considered during the design of both are approximately equal, the results are in agreement with (Fig. 1 b) the UK Standard of the bolt force calculation mode.

\section{Conclusion}

Based on the simulation analysis of four rows of eight high-strength bolt and vertical end plate extended with stiffening ribs, joint in the domain with diagonal stiffener of portal rigid frame beam column connections rigid joint shows that:

(1) The tension of the first row of bolt is always the biggest, the tension of the second row of bolts is very close to the tension of the first row of bolts. There is no obvious change in the tension force of the flange side of the compression flange.

(2) When designing, the force calculation model of high strength bolt is adopted in the model of Fig. 1/b, the center of the rotation of the joint is taken from the inner side (close to) the first row of bolt axis.

(3) When the design load is reached, the bending deformation of the end plate is small. The design model proposed in this paper is convenient and feasible.

\section{Acknowledgement}

Supported by the National Natural Science Foundation of China(Grant No. 51378051), Fok Ying Tung Education Foundation(Grant No. 122009) and Fundamental Research Funds for the Central Universities of Beijing Jiaotong University(Grant No. 2011JBZ008)

\section{References}

[1] CECS 102:2002 Technical specification for steel structure of light-weight building with gabled frames

[2] Chen Shaofan Design the beam-to-column connection of portal frames as rigid joint.[J]. Steel Construction, 2012(4):1-5.

[3] Shi Gang ,Shi Yongjiu Wang Yuanqing ,Li Shaofu, Chen Hong. Experimental study on bolt resistance for structural steel extended end-plate connections[J].Journal of Southeast University (Natural Science Edition), 2004,34(3):375-378.

[4]Shi Gang ,Shi Yongjiu Wang Yuanqing ,Li Shaofu, Chen Hong. Finite element and experimental analysis on bolted end- plate connections in steel portal frames[J]. China Civil Engineering Journal,2004,37(7):6-12.

[5] Liao Xinjun, Shi Yongjiu Wang Yuanqing, Chen Hong. Finite-element analysis of end-plate connection in light weight steel structure with gabled frames[J]. Building Science Research of Sichuan, 2005,31(2):1-4.

[6] Xu Weiliang, Fang Lei. Nonlinear finite element analysis for the behavior of semirigid end-plate connection. Building Science Research of Sichuan, 2011,37(5):4-7.

[7] Guo Bing, Gu Qiang. The strength and stiffness of beam to column end-plate connection in multi-story frames[J]. Journal of building structures. 2004,25(2):27-31.

[8] Jia Lianguang, Xing Guiyang, Wang Shengbo, Zhou Guangyu; Nonlinear Finite Element Analysis of High-Strength Bolt End-Plate Connection Joints [J]. Journal of shenyang Jianzhu university(natural science) , 2005,21(6);630-634. 
[9] Wang Sufang, Chen Yiyi. Calculation of initial stiffness of beam-to-column end-plate joint[J]. Engineering Mechanics. 2008,25(8):109-115.

[10]Guo Bing, Wang Lei, Wang Ying, Shi Yan, Tian Hailan; Experimental study on rotational stiffness of steel frame beam-column connections[J]. Journal of building structures. 2011,32(10):82-85.

[11]Eurocode3: Design of Steel Structures, Part 1.8: Design of Joints[S].2002

[12]GB 50007-2003,Code for design of steel structures[S]. 